\title{
Potential impacts of regional climate change on site productivity of Larix olgensis plantations in northeast China
}

\author{
Chenchen Shen ${ }^{(1-2-3)}$, Xiangdong Lei ${ }^{(3)}$, Hongyu Liu ${ }^{(3)}$, Lily Wang ${ }^{(1)}$, \\ Wanjun Liang ${ }^{(4)}$
}

Climate change is expected to substantially affect forest site productivity. However, its effects may vary depending on the climate scenario, region and tree species. We chose Larix olgensis in northeast China to investigate the responses of forest site productivity to regional climate change using a generalized additive model (GAM). Based on site index data and climate variables from 335 townships across the Jilin Province, we developed a climate-sensitive forest site index model, which accounted for $72.9 \%$ of the variation in the site index at the referred age of $20\left(\mathrm{SI}_{20}\right)$. Our results indicated that climatic and geographic factors significantly affect forest site productivity. The geographic location, mean annual temperature, mean annual precipitation and mean temperature differential were found to be statistically significant explanatory variables. We predict that the change of mean $S I_{20}$ would vary from $0.3 \mathrm{~m}$ to -0.8 $\mathrm{m}(2.2 \%$ to $-5.9 \%)$ by 2050 and from $0.5 \mathrm{~m}$ to $-1.6 \mathrm{~m}(3.7 \%$ to $-11.8 \%)$ by 2070 under three BC-RCP scenarios with rising temperature and increasing precipitation. Our study suggests that climate is an important factor affecting forest site productivity. Future climate changes could affect the forest site productivity both positively and negatively for Larix olgensis in northeast China. The relationship between climate and forest site productivity has strong implications for adaptive forest management and needs to be considered in forest management planning under future climate change.

Keywords: Site Productivity, Climate Change, Potential Impacts, Larix Olgensis

\section{Introduction}

Understanding how climate change affects forest site productivity is of great importance for adaptive forest management under climate change conditions. Forest site productivity, as a quantitative estimate of the potential for producing plant biomass at a site, is a significant indicator of forest quality, as well as an important variable of forest growth models in forest management (Skovsgaard \& Vanclay 2008). However, site productivity presents great spatial and temporal variability (Skovsgaard \& Vanclay 2013). Climate change directly or indirectly affects forest productivity due to rising atmospheric $\mathrm{CO}_{2}$ concentration and temperatures, changes in the amount and timing of precipitation and the interactions of forest ecosystems (Kirilenko \& Sedjo 2007, Medlyn et al. 2011). Experiments, observations and models indicate that the forest productivity changes with climate change, but the direction and magnitude of the effects are still uncertain (Medlyn et al. 2011). Using dominant height as a measure of site productivity, Bontemps et al. (2009) reported an increase of more than $50 \%$ in common beech at the end of the $20^{\text {th }}$ century in north-eastern France, whereas Badeau et al. (1995) found an increase of $27 \%$. Charru et al. (2010) found an increase

(1) Key Laboratory of Land Surface Pattern and Simulation, Institute of Geographic Sciences and Natural Resources Research, Chinese Academy of Sciences 86, 100101 Beijing (China); (2) University of Chinese Academy of Sciences 86, 100049 Beijing (China); (3) Institute of Forest Resource Information Techniques, Chinese Academy of Forestry 86, 100091 Beijing (China); (4) Jilin Academy of Forestry 86, 130033 Changchun (China)

(a) Xiangdong Lei (xdlei@ifrit.ac.cn)

Received: Dec 14, 2013 - Accepted: Oct 28, 2014

Citation: Shen C, Lei X, Liu H, Wang L, Liang W, 2015. Potential impacts of regional climate change on site productivity of Larix olgensis plantations in northeast China. iForest 8: 642651 [online 2015-03-02] URL: http://www.sisef.it/iforest/contents/?id=ifor1203-007

of $27.8 \%$ in stand basal area increment between 1977 and 1987, and a decrease of approximately 5\% between 1987 and 2004 . Both positive and negative estimated impacts on forest growth have been reported depending on the climate scenarios employed (Lutz et al. 2013).

One of the most widely used indicators of forest site productivity in forest management is the site index (SI), which is the mean height of the dominant trees growing on a site at a reference age (Carmean 1975, Skovsgaard \& Vanclay 2008). The site index is assumed to be constant over time, and thus included as a driving variable in forest growth and yield models. In reality, the site index often varies greatly due to changes in the genetic make-up of stands, climatic conditions and management practices (Monserud \& Rehfeldt 1990, Valentine 1997, Weiskittel et al. 2011). Empirical models have been developed to estimate the site index from climate, soil and vegetation information, thus allowing the possibility of predicting changes in the site index, forest growth and forest yield under climate change (McKenney \& Pedlar 2003, Nigh et al. 2004, Monserud et al. 2006, 2008, Albert \& Schmidt 2009, Aertsen et al. 2011, Nothdurft et al. 2012). The climate variables that influence the site index vary with species and sites, as do the magnitude of these variables (Messaoud \& Chen 2011). Nigh et al. (2004) developed climate-sensitive site index models of three species (spruce, lodgepole pine and Douglas fir) in the interior of British Columbia, Canada. They found that the site index for all species increased as the temperature rose, and that site index increased with precipitation for the two latter species. Monserud et al. (2006) found that the strongest linear predictors of site index for lodgepole pine were growing with degree days $>5{ }^{\circ} \mathrm{C}$ (the Julian date when degree days $>5{ }^{\circ} \mathrm{C}$ reaches 100) and the July mean temperature. They also found that climate could explain approximately one quarter of the variation in the lodgepole pine site index within the Alberta Province. Nothdurft et al. (2012) observed that only the site index of

\section{List of abbreviations}

The following abbreviations have been used throughout the paper:

- GAM: Generalised additive model

- SI: Site index

- DEM: Digital elevation model

- GCV: Generalised cross validation

- RCPs: Representative concentration pathways

- GCM: Global circulation models

- RMSE : Root mean square error

- VIF: Variance inflation factor 


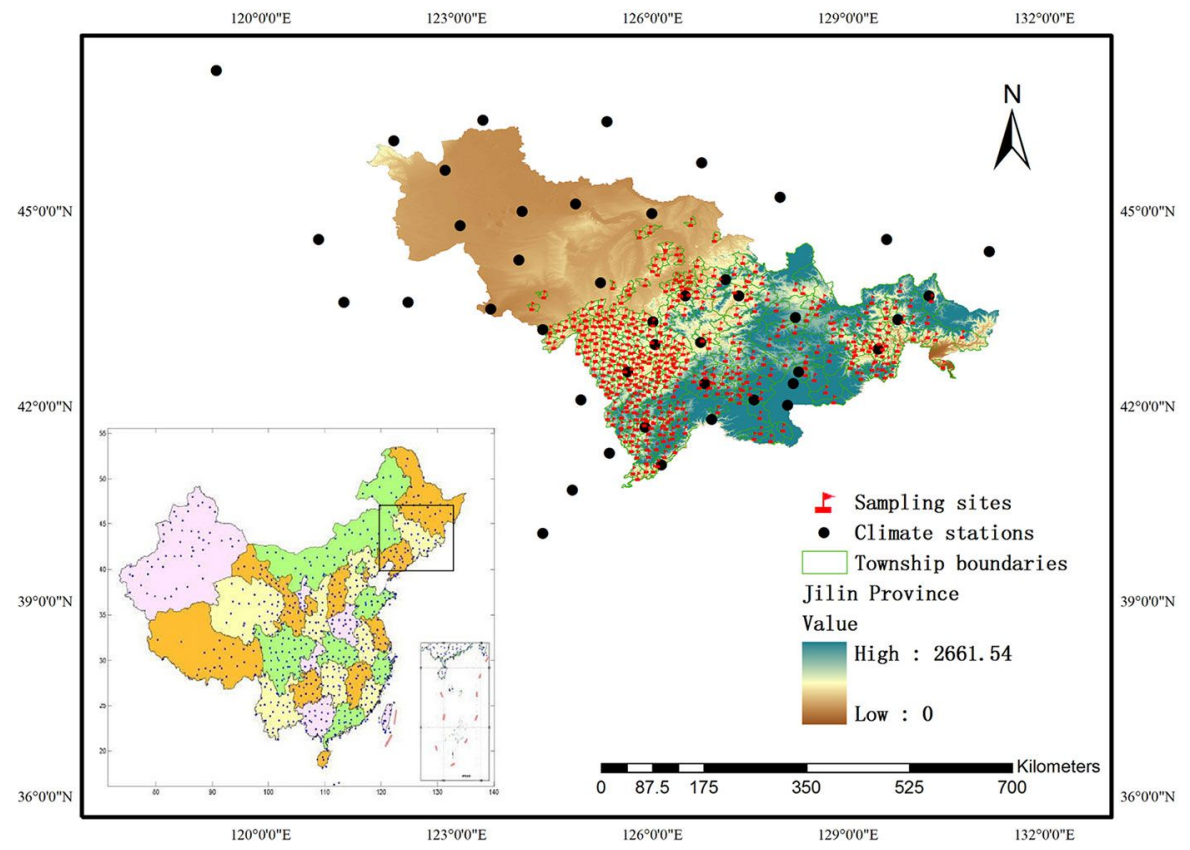

Fig. 1 - Distribution of sampling sites and climate stations used in the study. The "high-low" scale refers to the elevation ( $m$ a.s.l.).

Douglas fir continuously improved with increasing total precipitation over the growing season, while it reached an optimum value for other tree species.

A variety of modeling approaches have been successfully applied to predict the site index from climate and other environmental variables. For instance, studies have used parametric modeling, such as multiple linear and nonlinear regressions (Chen et al. 2002, McKenney \& Pedlar 2003, Nigh et al. 2004, Monserud et al. 2006, Bravo-Oviedo et al. 2007, Pinno et al. 2009), as well as nonparametric modeling, such as classification and regression trees (Aertsen et al. 2010, Afif-khouri et al. 2011), generalized additive models (Albert \& Schmidt 2009, Aertsen et al. 2010, 2011), artificial neural networks and boosted regression trees (Aertsen et al. 2010, 2011). After comparing the performance of five modeling techniques, Aertsen et al. (2011) concluded that non-parametric models, such as Generalized Additive Models (GAM), were superior to traditional multiple linear regression in site index predictions. In contrast to some modeling methods, GAM does not make a prior assumption about underlying relationships. The shape of the smoothing function is datadriven and allows for the visualization of the

Tab. 1 - Summary statistics of dominant tree age-height for Larix olgensis plots analyzed in this study. (STD): standard deviation; (CV): coefficient of variation.

\begin{tabular}{lllccc}
\hline Variable & Min & Max & Mean & STD & CV \\
\hline Age $(\mathrm{yrs})$ & 6 & 56 & 22.9 & 6.48 & 0.283 \\
Height $(\mathrm{m})$ & 3.5 & 22.3 & 13.7 & 3.19 & 0.233 \\
\hline
\end{tabular}

\section{Material and methods}

\section{Study area and data collection}

The Jilin Province is located in the mid northeastern China $\left(40^{\circ} 52^{\prime}-46^{\circ} 18^{\prime} \mathrm{N}, 121^{\circ}\right.$ $38^{\prime}-131^{\circ} 19^{\prime} \mathrm{E}-$ Fig. 1), and is one of the most important forest regions of the country. This area belongs to the temperate continental monsoon climate type with four distinct seasons. The mean temperature is $>23{ }^{\circ} \mathrm{C}$ in the summer and $<-11^{\circ} \mathrm{C}$ in winter. The annual frost-free period is approximately 100 to 160 days. The average annual precipitation is approximately 400 to $600 \mathrm{~mm}$, mostly concentrated in the summer.

Site index data were taken from a previous study already published (Liang et al. 1999). In 1999, we set 335 temporary rectangular plots of 0.06 ha across 335 townships of the Jilin Province spread over the distribution area of Changbai larch plantations (Fig. 1). In each plot, five dominant trees were selected and their height and age were recorded. Tree age was taken from subcompartment documents. The summary statistics of the trees' height and age are displayed in Tab. 1. Based on stand age and average dominant height, a site index model was created by the guide curve method (Meng 2006) using the software package ForSTAT (a professional forestry statistics software developed by the Chinese Academy of Forestry Tang et al. 2009). We randomly chose $80 \%$ of the data for model calibration and the remaining $20 \%$ for model validation. Finally, the site index of all plots predicted by the model was used as a driving variable in modeling the relationship between the site index and climate.

Basic climate data were provided by the China Meteorological Data Sharing Service System (CMDSSS 2011). To assign climate variables to each plot, geographic and basic meteorological data from 1961 to 2010 (latitude, longitude and altitude, daily and monthly mean temperature, minimum and maximum temperature, precipitation, radiation hours and relative humidity) were first collected from 43 weather stations spread within and around the Jilin Province. Climate data were then spatially interpolated to obtain values for every site in the province based on its elevation and geographic location. To this purpose, we used the professional spatial interpolation software ANUSPLIN $^{\circledR}$ v. 4.36 based on the FORTRAN programming language and developed at the Australian National University (Hutchinson 2006). The working principle of the software derives from ordinary thin plate and partial thin plate smoothing for multi-data interpolation (Hutchinson 2006). We used a highquality digital elevation model (DEM) in this study, obtaining a resolution of interpolated values of $300 \mathrm{~m}$. The variables subjected to interpolation were monthly and an- 
Tab. 2 - Descriptive statistics for candidate climate variables used in the model simulation. (STD): standard deviation; (CV): coefficient of variation.

\begin{tabular}{|c|c|c|c|c|c|c|c|}
\hline Label & Variable description & Units & Mean & STD & $\mathbf{C V}$ & Min & Max \\
\hline MAT & mean annual temperature & ${ }^{\circ} \mathrm{C}$ & 4.9 & 1.12 & 0.229 & -0.4 & 8.1 \\
\hline AMAXT & annual maximum temperature & ${ }^{\circ} \mathrm{C}$ & 19.2 & 1.04 & 0.054 & 13.9 & 21.2 \\
\hline AMINT & annual minimum temperature & ${ }^{\circ} \mathrm{C}$ & -9.4 & 1.41 & -0.150 & -15.3 & -5.2 \\
\hline MTWM & mean maximum temperature in the warmest month & ${ }^{\circ} \mathrm{C}$ & 21.5 & 1.32 & 0.061 & 16.7 & 23.7 \\
\hline MTCM & mean minimum temperature in the coldest month & ${ }^{\circ} \mathrm{C}$ & -16.0 & 1.21 & -0.076 & -20.7 & -11.8 \\
\hline GSMAXT & mean maximum temperature during growing season & ${ }^{\circ} \mathrm{C}$ & 35.3 & 1.04 & 0.029 & 30.64 & 38.2 \\
\hline GSMINT & mean minimum temperature during growing season & ${ }^{\circ} \mathrm{C}$ & -11.9 & 1.90 & -0.160 & -20.24 & -6.9 \\
\hline MTD & mean temperature differential & ${ }^{\circ} \mathrm{C}$ & 28.6 & 0.75 & 0.026 & 26.1 & 30.1 \\
\hline GSAT & accumulated temperature higher than $5^{\circ} \mathrm{C}$ during growing season & ${ }^{\circ} \mathrm{C}$ & 2928 & 228.87 & 0.078 & 2038 & 3320 \\
\hline MAP & mean annual precipitation & $\mathrm{mm}$ & 691 & 77 & 0.111 & 542 & 901 \\
\hline GSP & mean precipitation during growing season & $\mathrm{mm}$ & 99 & 10 & 0.101 & 79 & 132 \\
\hline MR & mean annual radiation hours & $\mathrm{h}$ & 2388 & 80.6 & 0.034 & 2259 & 2665 \\
\hline GSR & mean radiation hours during growing season & $\mathrm{h}$ & 215 & 9.3 & 0.043 & 195 & 240 \\
\hline MRH & mean annual relative humidity & $\%$ & 71 & 1.8 & 0.025 & 65 & 78 \\
\hline GSRH & mean relative humidity during growing season & $\%$ & 70 & 1.9 & 0.027 & 64 & 74 \\
\hline
\end{tabular}

nual mean temperature, mean minimum temperature, mean maximum temperature, total precipitation, total radiation hours, mean relative humidity and the accumulated temperature above $5^{\circ} \mathrm{C}$ during the growing season. Using all the monthly climate data, we could calculate the annual climate parameters over the period 1961-2010, thereby the climate change in recent decades could be analyzed on a $300 \times 300 \mathrm{~m}$ grid. The generalized cross validation (GCV) method was applied on the spatially-interpolated climate dataset, revealing a high accuracy of simulations. Such spatially-interpolated dataset was then used in the analyses of climate change and in the modeling of climate-sensitive site index.

The candidate climatic variables for later model calibration are listed in Tab. 2. They were calculated as the mean annual values from the planting to the inventory year for the climate-sensitive site index model (eqn. $1)$.

$$
\begin{aligned}
G C V & =\frac{\left\|W^{-1}(I-A) z\right\|^{2} / N}{[\operatorname{trace}(I-A) / N]^{2}} \\
& =\frac{M S R}{(E D F / N)^{2}}=M S E+\sigma^{2}
\end{aligned}
$$

where $A$ is an $N \times N$ matrix called the influence matrix; $W$ is the diagonal matrix with $N \times N$; $\operatorname{trace}(I-A)$ is the number of effective degrees of freedom (EDF); MSR is the weighted mean residual sum of squares; $M S E$ is the mean square error of the fitted function; $\sigma^{2}$ is the variance.

To analyse the shifts in site index values due to changing climatic conditions, the $S I$ of each plot in the reference period 19611999 was compared with that predicted for the period 2041-2080. Then the climate-sensitive model was applied under three Representative Concentration Pathways (RCPs) which are the most recent GCM (Global Climate Models) projections used in the Fifth Assessment IPCC report (Moss et al. 2008).
The three RCPs included (i) a mitigation scenario leading to a very low forcing level (RCP2.6); (ii) a medium stabilization scenario (RCP6.0); and (iii) a very high-baseline emission scenario (RCP8.5 - Moss et al. 2008, Van Vuuren et al. 2011). These future climate data were obtained with a resolution of $1 \times 1 \mathrm{~km}$ in BCC-CSM1-1 for the time periods 2050 (average for 2041-2060) and 2070 (average for 2061-2080) from the dataset of the World Climate Research Programme (http://cmip-pcmdi.llnl.gov/cmip5/).

\section{Site index equation}

A guide curve method was utilized for estimating the site index values from the mean dominant height and age. Five widely used and highly flexible growth functions, including the Logistics model, the Richards model, the Levakvic model, the Gompertz model and the Hossfeld model, were selected and calibrated for the development of a guide curve. According to model performances, the Richards model was adopted as the guide curve. The final model equation was (eqn. 2):

$$
S I_{t_{0}}=H_{t} \frac{\left(1-e^{-0.0546 t_{0}}\right)^{1.3634}}{\left(1-e^{-0.0546 t}\right)^{1.3634}}
$$

where $S I 0$ is the site index at the reference age $t_{0}$, which was 20 in this study (Liang et al. 1999), indicated as $S I_{20}$ henceforth; $H_{\mathrm{t}}$ is the stand dominant height at the age $t$. The coefficient of determination obtained for the above equation was $R^{2}=0.86$. No significant differences were found between the predicted and observed values after validation test $(p>0.05)$. The absolute and percent root mean square error (RMSE) values of the model obtained were $0.23 \mathrm{~m}$ and 0.017 , respectively. We also verified the model reliability through a placement test, that showed that $99.7 \%$ of the values are within the interval of site index curves (Fig. 2). The $S I_{20}$ of each site analyzed was estimated from the eqn. 2.

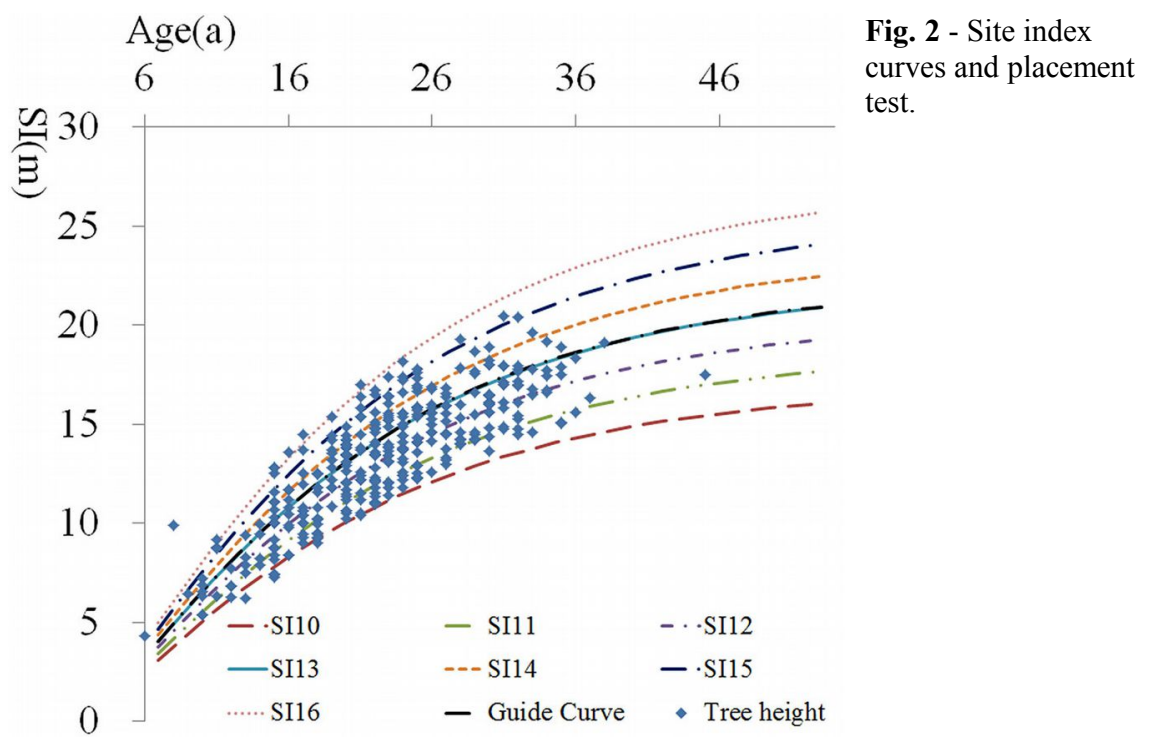




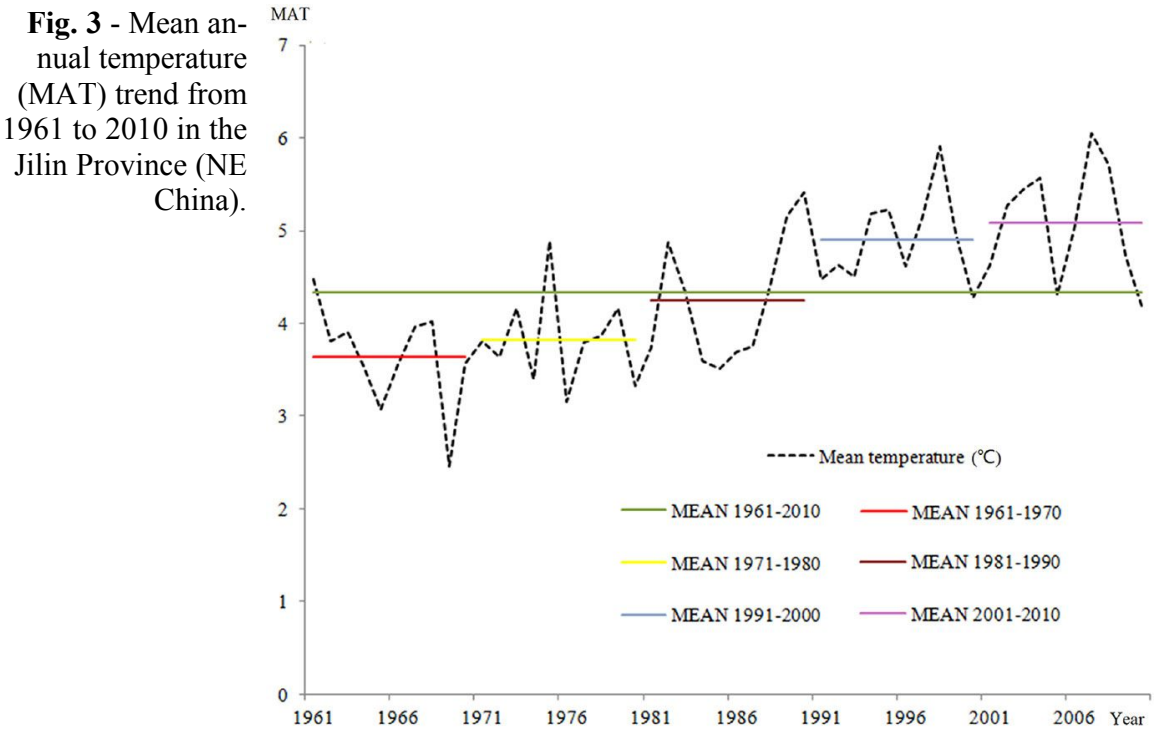

Fig. 4 - Mean an- M nual precipitation (MAP) trend from 1961 to 2010 in the Jilin Province (NE China).

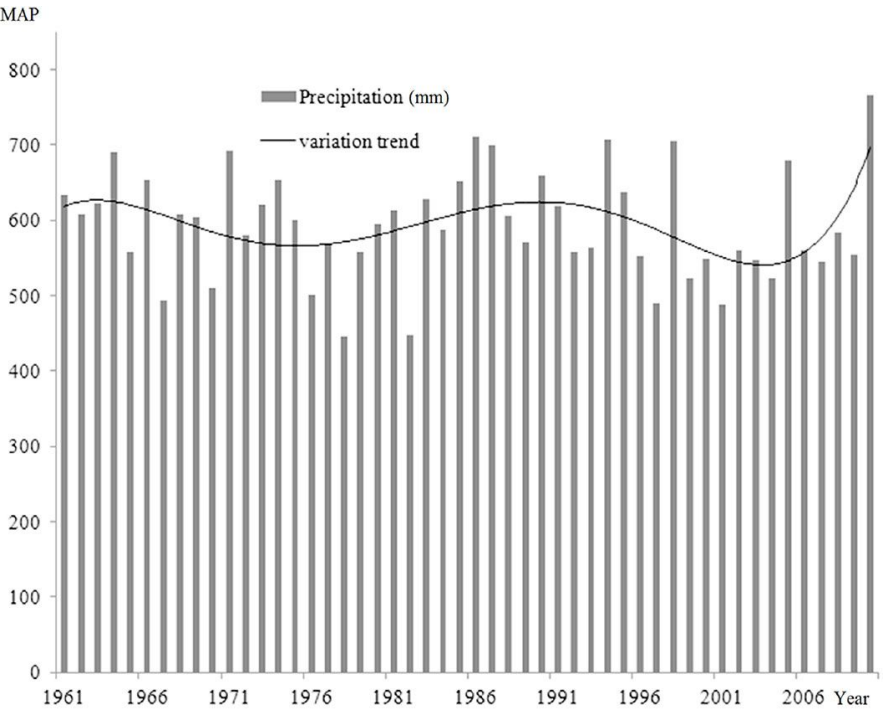

\section{Climate-sensitive site index modeling}

Generalized Additive Models (GAM) are powerful tools making use of smooth functions that can adequately describe complex, possibly nonlinear relationships in ecology (Hastie 1990, Austin 2002). In this study, we selected GAM to develop a climate-sensitive site index model based on the estimated $S I_{20}$ values and the climatic variables from 1961

Tab. 3 - Estimated coefficients and cross validation statistics for the GAM. ( $\left.{ }^{* * *}\right)$ : $p<0.0002$

\begin{tabular}{lcccccc}
\hline Parameter & $\begin{array}{c}\text { Coeff./ } \\
\text { Smooth }\end{array}$ & Estimate & $\begin{array}{c}\text { Standard } \\
\text { error }\end{array}$ & $\begin{array}{c}\text { Estimated } \\
\text { degree of } \\
\text { freedom }\end{array}$ & F & P-value \\
\hline Intercept & $\beta_{0}$ & 2.693 & 0.009 & - & - & - \\
LL (Long/Lat) & $f_{1}$ & - & - & 20.661 & $24.42<2 \mathrm{e}^{-16 * * *}$ \\
MAT & $f_{2}$ & - & - & 1.000 & 33.47 & $1.75 \mathrm{e}^{-8 * * *}$ \\
MAP & $f_{3}$ & - & - & 1.000 & $323.77<2 \mathrm{e}^{-16 * * *}$ \\
MTD & $f_{4}$ & - & - & 3.159 & 14.38 & $1.19 \mathrm{e}^{-10 * * *}$ \\
Adjusted R & & - & 0.77 & - & - & - \\
Deviance explained (\%) & - & 72.9 & - & - & - & - \\
$G C V$ score & - & 0.037 & - & - & - & - \\
\hline
\end{tabular}

imprecise for very young stands (Weiskittel et al. 2011). The generalized additive model adopted to represent the relationships between the site index, climate variables and spatial variation was (eqn. 3 ):

$$
S I_{20}=\beta_{0}+\sum_{i=1}^{k} f_{i}\left(\text { climate }_{i}\right)+f_{i}(\text { lat }, \text { long })+\varepsilon
$$

where $S I_{20}$ is the site index; $\beta_{0}$ is the intercept; $f_{\mathrm{i}}$ and $f_{\mathrm{j}}$ are smooth functions of climate variables $(i=1$ to $\mathrm{k})$ and geographic location, respectively; and $\varepsilon$ is the random error. All computations were carried out using the MGCV package in the $\mathrm{R}$ platform (Wood 2006, R Development Core Team 2007). The MGCV uses generalized cross validation for the model selection, producing a statistically defensible degree of smoothing, which avoids over-fitting and lowers the computing cost. The $G C V$ value or score could be considered as an estimate of the mean square prediction error based on a leave-one-out cross validation estimate process (Clark 2013). The optimal roughness of the smooth terms was determined by minimizing the $G C V$ value. A model with a lower $G C V$ value has more explanatory power and is preferred to models with higher values. The values of F-statistic calculated from the GAM indicated the relative importance of independent variables to the site index. Multi-collinearity of explanatory variables was tested by calculating the variance inflation factor (VIF), and correlated climate variables showing VIF $>5$ were discarded. Because of multiple testing, Bonferroni correction was applied for statistical significance. Model residuals were also examined graphically to check that model assumptions were not violated. Climate variables were obtained from spatially interpolated climatic data estimated as described above.

\section{Results}

\section{The climate change of Jilin Province from 1961 to 2010}

Fig. 3 and Fig. 4 show the changes in mean annual temperature (MAT) and precipitation (MAP), respectively, obtained for the Jilin Province over the period 1961-2010 using the interpolated dataset. A fluctuating, rising trend of MAT was observed, whose increase was even more obvious when MAT values were averaged over the last five decades. Contrastingly, mean annual precipitation varied in the same period from 500 to $700 \mathrm{~mm}$, with no prevalent trends. Nonetheless, a sharp increase of precipitation was detected in the latest decade after a significant reduction. These results agree with previous studies on climate change in the northeast region of China (Zhao \& Luo 2007, Qu et al. 2008, Tao \& Zhang 2010), which predicted that temperature precipitation would both increase in northeast China in the $21^{\text {st }}$ century 
Fig. 5 - Analysis of residuals and response values obtained by the application of the generalized additive model.

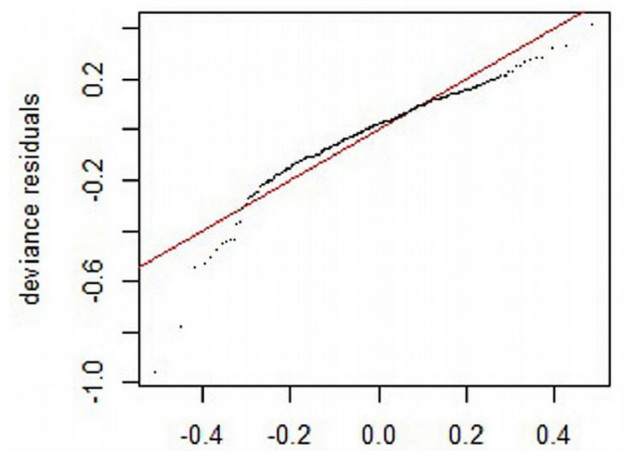

theoretical quantiles

Histogram of residuals

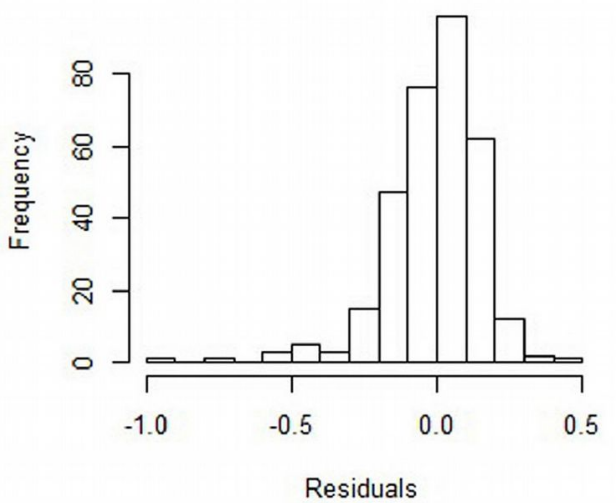

Resids vs. linear pred.

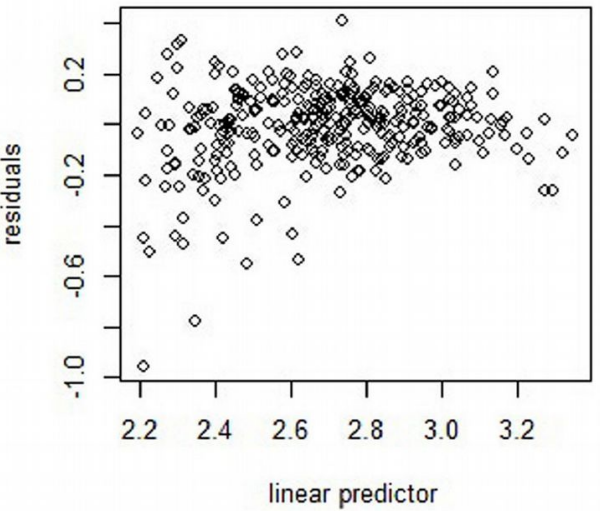

Response vs. Fitted Values

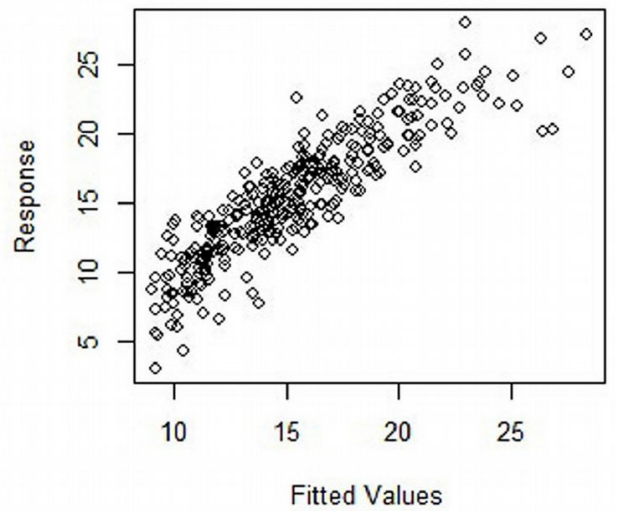

Fig. 6 - The partial effect of longitude and latitude on the $S I_{20}$.

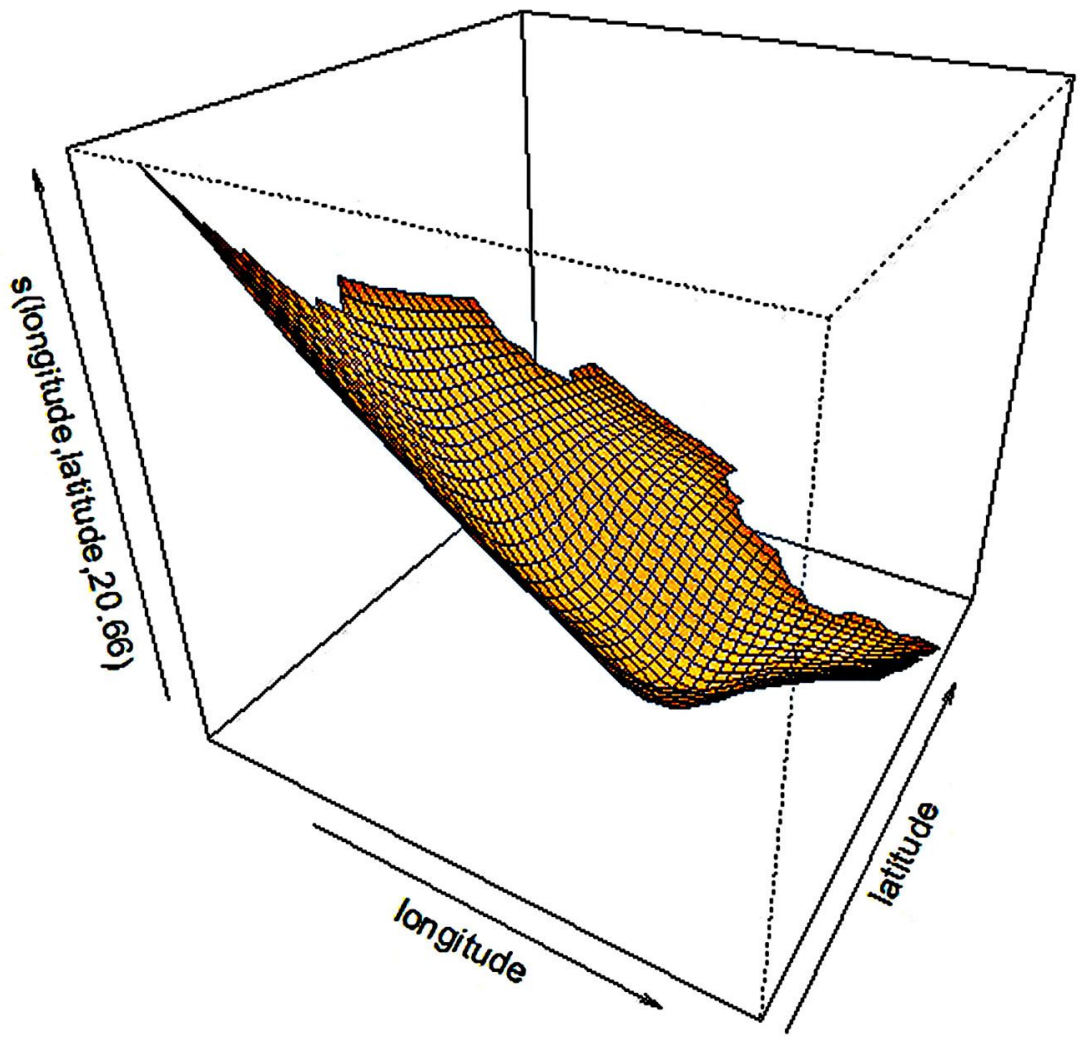


Fig. 7 - Partial effect of the MAT on the $S I_{20}$.

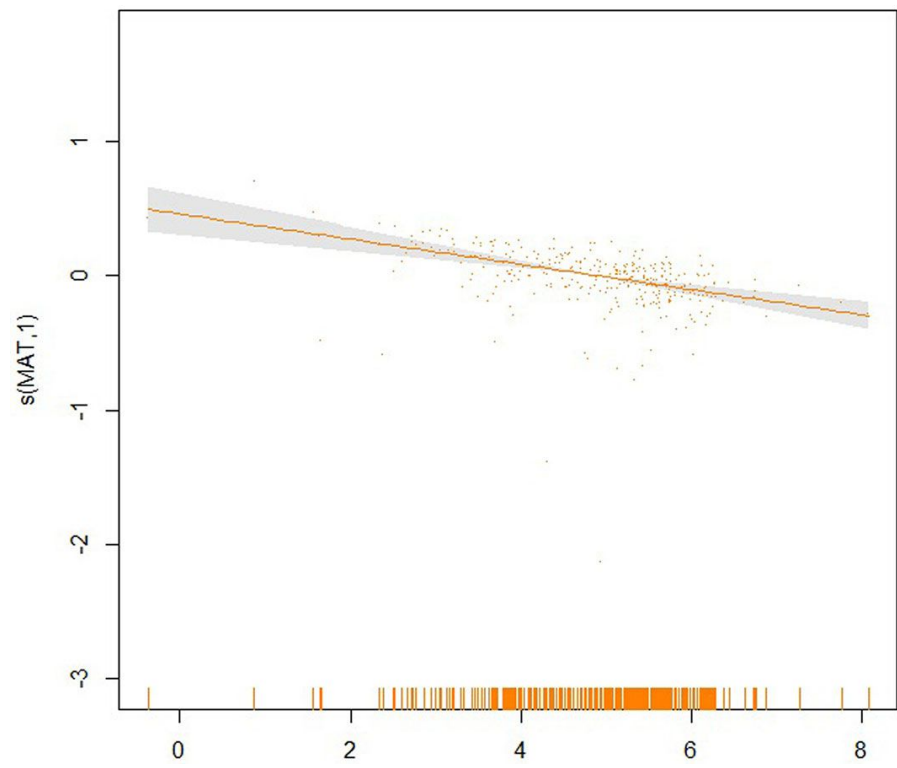

Fig. 8 - Partial effect of the MAP on the $S I_{20}$.

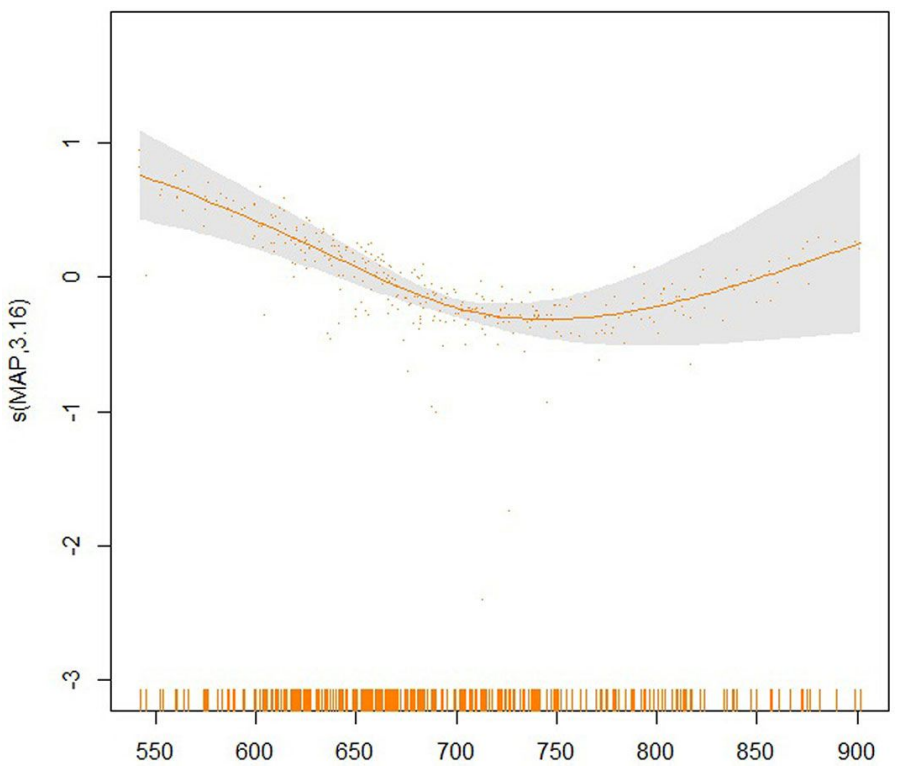

Fig. 9 - Partial effect of the MTD on the $S I_{20}$.

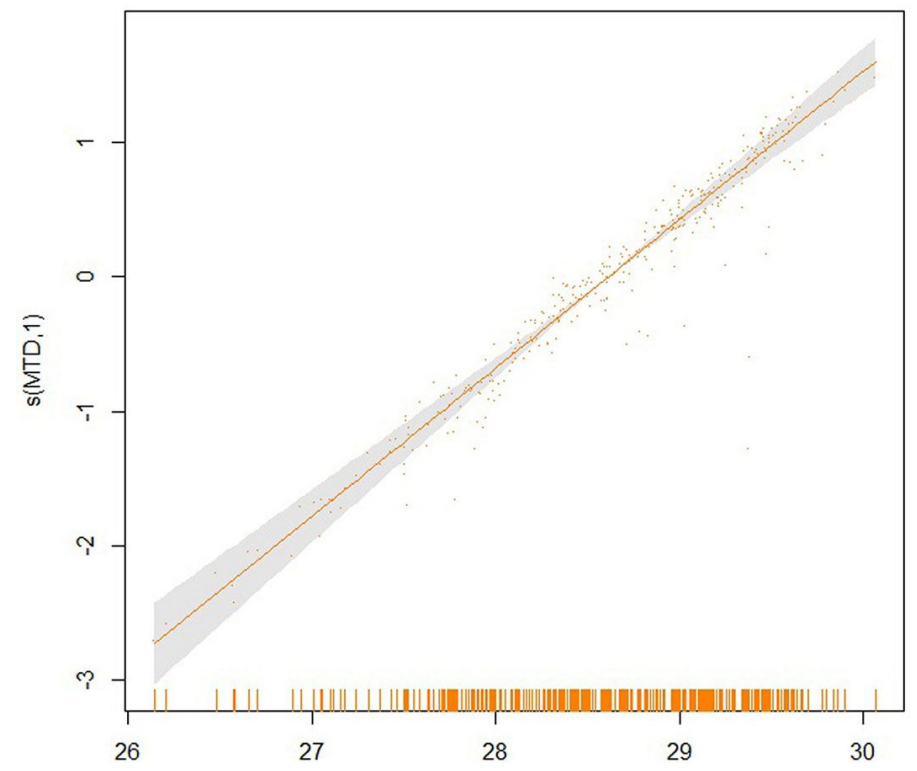

based on IPCC climate scenarios and other prediction models.

Climate-sensitive site index model

Fitting statistics and estimated values of the GAM applied are summarized in Tab. 3. All smooth terms are very significant with $\alpha=$ 0.001 after Bonferroni correction, and biologically meaningful. Longitude and latitude (LL), MAT, MAP and MTD were the significant explanatory variables. Overall, the climate variables and the geographic location included in the model could account for $72.9 \%$ of the variation in the $S I_{20}$. The small $G C V$ score obtained (0.037) indicated a good fit of the projection on the data, as confirmed by the low RMSE $(0.83 \mathrm{~m})$. The QQ plot, residual plot and histogram (Fig. 5) indicated that residuals were normally distributed, with no obvious evidence of heteroscedasticity. The fitted values were quite consistent with the modeled values (Fig. 5).

The partial effects of the four significant model predictors on the parameter $S I_{20}$ are shown in Fig. 6 to 9. The partial effect surface of longitude and latitude (Fig. 6) reveals the relationship between the geographic location and the $S I_{20}$. In the Jilin Province, the site index decreases eastbound and northbound, reaching the lowest value in the central-northern part of the province, likely due to the altitude change. MAT has a linear negative effect on $S I_{20}$, though a larger uncertainty exists at the lowest and the highest temperatures (Fig. 7). The effect of MAP on $S I_{20}$ appeared more complicated, in that $S I_{20}$ decreases with increasing MAP up to about $720 \mathrm{~mm}$, and then increases for higher values (Fig. 8). On the contrary, MTD had a strong linear positive impact on $\mathrm{SI}_{20}$ (Fig. 9).

\section{Predicting site index response to future} climate change

For predicting the change of $S I_{20}$ in response to future climate change, we applied three RCPs climate scenarios from the IPCC. The results showed that from 2040 to 2080 MAT would increase by 1.3 to $3.5^{\circ} \mathrm{C}$, while MAP would increase by 8 to $26 \%$ (Tab. 4 ). Changes of $S_{20}$ across all sites showed spatial heterogeneity in terms of magnitude and direction under each scenario. Compared with mean $S I_{20}$ under the current climate conditions $(13.6 \mathrm{~m})$, an increase to $13.9 \mathrm{~m}$ $(2.2 \%)$ by 2050 and $14.1 \mathrm{~m} \mathrm{(3.7 \% )} \mathrm{by} 2070$ was predicted under the BC-RCP2.6 scenario. However, the mean $S I_{20}$ across Changbai Larch distribution areas would decrease gradually under the remaining two climate scenarios both in 2050 and 2070. Specifically, The mean $S I_{20}$ would decrease by 0.4 $\mathrm{m}(-2.9 \%)$ and $0.8 \mathrm{~m}(-5.9 \%)$ by 2050 and by $0.9 \mathrm{~m}(-6.6 \%)$ and $1.6 \mathrm{~m}(-11.8 \%)$ by 2070 under BC-RCP6.0 and BC-RCP8.5, respectively. These results indicate that $\mathrm{SI}_{20}$ will increase under climate scenarios with 
Tab. 4 - Prediction of the mean $S I_{20}$ changes across the Changbai Larch distribution areas under IPCC climate scenarios. (MAT): mean annual temperature; (MAP): mean annual precipitation; $\left(S I_{20}\right)$ : site index at the reference age of 20 years.

\begin{tabular}{|c|c|c|c|c|c|c|c|c|c|c|}
\hline \multirow{2}{*}{$\begin{array}{c}\text { Time } \\
\text { period }\end{array}$} & \multirow{2}{*}{$\begin{array}{l}\text { Climate } \\
\text { scenario }\end{array}$} & \multicolumn{3}{|c|}{ MAT $\left[{ }^{\circ} \mathrm{C}\right]$} & \multicolumn{3}{|c|}{ MAP $[\mathrm{mm}]$} & \multicolumn{3}{|c|}{$S I_{20}[\mathrm{~m}]$} \\
\hline & & DMAT & Mean & STD & МMAP (\%) & Mean & STD & $\Delta S I_{20}$ & Mean & STD \\
\hline- & Current & 0 & 4.9 & 1.118 & 0 & 691 & 77.1 & 0 & 13.6 & 2.69 \\
\hline 2050 & BC-RCP2.6 & 1.3 & 6.2 & 1.091 & 8 & 751 & 113.3 & $0.3(2.2 \%)$ & 13.9 & 5.33 \\
\hline \multirow{2}{*}{$(2041-2060)$} & BC-RCP6.0 & 1.9 & 6.8 & 1.087 & 16 & 802 & 116.1 & $-0.4(-2.9 \%)$ & 13.2 & 5.86 \\
\hline & BC-RCP8.5 & 2.4 & 7.3 & 1.094 & 18 & 818 & 123.1 & $-0.8(-5.9 \%)$ & 12.8 & 5.65 \\
\hline \multirow{3}{*}{$\begin{array}{c}2070 \\
(2061-2080)\end{array}$} & BC-RCP2.6 & 1.3 & 6.2 & 1.086 & 22 & 843 & 131.7 & $0.5(3.7 \%)$ & 14.1 & 5.94 \\
\hline & BC-RCP6.0 & 2.3 & 7.2 & 1.081 & 26 & 868 & 139.2 & $-0.9(-6.6 \%)$ & 12.7 & 5.33 \\
\hline & BC-RCP8.5 & 3.5 & 8.4 & 1.096 & 23 & 852 & 131.3 & $-1.6(-11.8 \%)$ & 12.0 & 5.71 \\
\hline
\end{tabular}

less forcing emissions, and decline under scenarios with more forcing emissions Based on the above results, it might be hypothesized that excessive greenhouse gases in forcing emissions would lead to the inhibition of tree growth.

\section{Discussion}

\section{Climate-sensitive site index model}

Despite of its limitations, the site index is the most widely used indicator for quantifying forest site productivity and analyzing forest growth (Skovsgaard \& Vanclay 2008). Using traditional growth and yield models, it is difficult to predict forest growth under climate change because the site index is always assumed to be constant (Fontes et al. 2010, Mäkelä et al. 2012). Although process-based models are still widely used, recent models describing the relationships between the site index and environmental/climatic factors have the potential to facilitate the prediction of timber production in the context of environmental change (Monserud et al. 2006, Albert \& Schmidt 2009). In this study, we developed a climate-sensitive site index model using the GAM method. Both geographic location and climate factors, including mean annual temperature, mean annual precipitation and mean temperature differential, were used as predictors. Among these variables, geographic location played a significant role in quantifying site index, in accordance with findings by Monserud et al. (2008) and Albert \& Schmidt (2009). Spatial variability of the site index was also confirmed by another recent investigation by Skovsgaard \& Vanclay (2013). Most studies have shown that climatic variables, especially those related to warmth and moisture (evapotranspiration, mean annual temperature, mean annual precipitation, etc), are effective and useful predictors of site productivity. For instance, Monserud et al. (2006) found that the strongest predictors in their site index model for lodgepole pine were all related to heat. The relationships between the site index of maritime pine and the climatic and environmental factors were investigated by BravoOviedo et al. (2011), who found that the site qualities were better in warm and humid sites than in cold and dry sites. Moreover, some composite climate variables (e.g., the ratio of the mean annual temperature to the mean annual precipitation, the ratio of summer precipitation to annual precipitation and the summer-winter temperature differential) have also been used for site index modeling (Nigh et al. 2004, Weiskittel et al. 2011), demonstrating the complicated interaction among climate variables. The adjusted $\mathrm{R}^{2}$ statistics of all these site index models ranged from 0.08 to 0.91 , and $90 \%$ ranged from 0.2 to 0.6 (Chen et al. 2002, Nigh et al. 2004, Bravo-Oviedo et al. 2007, 2011, Pinno et al. 2009, Nigh 2010). There are huge differences in climate variables and modeling results among these studies, indicating that the relationship between forest site productivity and climate is still uncertain to some extent. Process-based or hybrid representations of the relationship between climate and productivity are needed (Peng et al. 2002, Coops et al. 2010, Bravo-Oviedo et al. 2010). Using spatial and climatic variables, our empirical model could explain $72.9 \%$ of the site index variation. In addition to climate factors, the site index is also affected by soil and local environmental variables (Hamel et al. 2004, Latta et al. 2009, Pinno et al. 2009, Bravo-Oviedo et al. 2011). The effects of soil variables on the site index of larch will be the subject of future study.

\section{Site index response to climate change}

Temperature, light, water and nutrient availability are the key drivers of forest productivity that may be affected by future climate change. In the context of global warming, the effect of rising temperatures on site productivity have been examined and both positive and negative impacts have been reported (Loustau et al. 2005, Ollinger et al. 2008, Kellomäki et al. 2008, Chiang et al. 2008, Latta et al. 2009, Coops et al. 2010, Kirschabum et al. 2012). Quantifying such effect is still challenging, because the temperature simultaneously affects ecosystem processes (photosynthesis, respiration, transpiration, allocation, decomposition, etc.). Moreover, the effects of rising temperature are in part the result of its interaction with precipitation and the adaptability of plants to temperature change. This difficulty is further worsen by the frequent nonlinear nature of the impacts (Medlyn et al. 2011).

In our study, the application of a generalized additive model revealed that rising temperatures have a partial negative effect on site index of larch plantations in the studied region (Fig. 7), but such effect varied with increasing precipitation (Tab. 4), a scenario which is more complicated than that reported by previous studies in other regions (Albert \& Schmidt 2009). Temperature controls the rate of plant metabolism, which in turn controls the amount of photosynthesis that can take place. However, a higher temperature also increases evaporative demand causing water stress that would hinder tree growth. Consequently, potential drought stress in the Jilin Province would negatively affect the site index. The mean annual precipitation displays a typical nonlinear effect on site index in this study. Changes in precipitation are spatially variable and highly uncertain, though a tendency towards more abrupt and intense precipitation is expected under climate change. Abrupt rainfall would greatly challenge the water storage capacity of the soil, which would result in too high soil moisture that would weaken the respiration of plant roots. In addition, the increased runoff would lead to an increased leakage of nutrients from soil. These two aspects of increasing precipitation would also negatively affect the site index. However, the situation would change when the mean annual precipitation reaches a threshold of approximately $720 \mathrm{~mm}$ (Fig. 8), i.e., continuous rainfall could ease and compensate the hydrological stress caused by rising temperature. Although there is still much uncertainty, our study shows that climate is clearly a significant driver of the change in the site index.

\section{Predicting the response of site index to climate change}

Climate change has significant effects on forest site productivity; however, the direction and magnitude of such effects are still uncertain and dependent on the climate change scenario, tree species and region (Medlyn et al. 2011, Weiskittel et al. 2011). We found that the average $S I_{20}$ of Larix ol- 
gensis varies from $0.3 \mathrm{~m}(2.2 \%)$ to $-0.8 \mathrm{~m}$ $(-5.9 \%)$ by 2050 and from $0.5 \mathrm{~m}(3.7 \%)$ to $-1.6 \mathrm{~m}(-11.8 \%)$ by 2070 , as a consequence of the increasing temperature and precipitation. The increase of site productivity of larch with rising temperature and precipitation was projected from both empirical (L 2006) and process-based models (Peng et al. 2009). Uncertainty in the model prediction of site index under climate change was also observed in previous studies. Monserud et al. (2008) used a nonlinear general circulation model to predict that the site index of lodgepole pine in Alberta (Canada) would increase by $26 \%$ to $35 \%$. Albert \& Schmid (2009) analyzed the site index under the A1B future climate scenario (IPCC 2007), predicting a change for the period 20412050 that varied from $-1.19 \mathrm{~m}$ to $-2.87 \mathrm{~m}$ $(-4.4 \%$ to $-10.5 \%)$ with decreasing precipitation and from $-0.24 \mathrm{~m}$ to $2.05 \mathrm{~m}(-0.8 \%$ to $7.7 \%$ ) with increasing temperature. BravoOviedo et al. (2010) found that the change in site index prediction of Spanish Pinus pinaster fluctuated greatly between $-30 \%$ and $12.5 \%$. Coops et al. (2010) found that the site index of Douglas fir in the interior varied in an opposite manner to the variation along the coast. Weiskittel et al. (2011) reported that the predominant trend from 2000 to 2090 was a $0-5 \mathrm{~m}(0-30 \%)$ increase in the average site index across forests of the western part of the United States, though the site index in some areas would decrease by ap proximately $30 \%$. Nothdurft et al. (2012) predicted that the site index would decrease in low areas and increase at high altitudes in the mid- $21^{\text {st }}$ century. For the Norway spruce, Douglas fir, Scots pine, sessile oak and common beech, the site index would remain high based on scenario B1, whereas it would decrease based on scenarios $\mathrm{A} 1 \mathrm{~B}$ and $\mathrm{A} 2$ in most areas. Because of the differences in model input, climate scenario, tree species, location and scale, the outputs of the site in dex change are difficult to compare. When using model outputs for the site index under future climate change, caution should be taken because of the uncertainty arising from the different climate scenarios, model errors and plant ability to acclimate and adapt to climate change (Albert \& Schmidt 2009, Coops et al. 2010, Medlyn et al. 2011). Nonetheless, models still provide useful information for adaptive management in response to climate change despite these uncertainties.

\section{Implications for forest management planning of larch plantations}

Adaptive forest management strategies at both landscape and stand levels are needed to meet the challenge of climate change. China released its Forestry Action Plan to address climate change, which advocated a combination of mitigating and adapting mea- sures (SFA 2008). Climate change is not currently considered in forest management plans. Understanding the potential impacts of climate change on forest productivity is useful for incorporating climate change into forest management plan and silvicultural decision-making process. Currently, the annual allowable cut and rotation age are determined by empirical growth and yield models based on historical data, which do not and cannot respond to current or future climate scenarios (Johnson \& Williamson 2005). Empirical models with a climate-sensitive site index as an important driving variable could project future growth and yield under climate change, thus providing forest managers with a useful tool for adapting their plans. Under future climate change in the Jilin Province, we found both an increase and a decrease of average $\mathrm{SI}_{20}$ for Larix olgensis from 2041 to 2080, with a magnitude varying from $3.7 \%$ to $-11.8 \%$. Therefore, local specific management should be adapted according to the above predictions.

At the landscape scale, the spatial prediction of site index changes in relation to climate change would be of great importance to newly established and current larch plantations. Indeed, when establishing new plantations, it is recommended replanting at future productive sites with more robust genotypes. Diversification of tree species mixtures and management approaches would increase the adaptive capacity and improve the overall resilience of the regional forest ecosystem. For example, prolonged rotations or conversion with other tree species may be needed where site productivity is lowered, while a shorter rotation may be necessary for timber production where site productivity is enhanced. Furthermore, management might focus on currently productive sites and those likely to remain productive under future climate scenarios, reducing the efforts on poor sites. These adaptive measures should be integrated with the impacts of other environmental variables, such as soil and climate-induced forest health and loss. Additionally, owing to some uncertainties related to climate change, the management and analysis of risk should be considered in long-term forest management planning.

\section{Conclusions}

A climate-sensitive index model was developed using a generalized additive model for Larix olgensis in the Jilin Province (northeastern China). We found that the effective predictors are geographic location, mean annual temperature (MAT), mean annual precipitation (MAP) and mean temperature differential (MTD). The MAT and MTD showed linear negative and positive effects on the site index, whereas the MAP showed obvious nonlinear effects. Under the BCRCP scenarios of IPCC from 2041 to 2080 , the change of average site index of Larix olgensis varies from $0.5 \mathrm{~m}(3.7 \%)$ to $-1.6 \mathrm{~m}$ $(-11.8 \%)$ with increasing temperature and precipitation. Our findings indicate that the impact of future climate change on forest site productivity of Larix olgensis could be both beneficial and adverse depending on the regional cliate change scenario considered. In addition, a remarkable spatial variability of site index change was found. The model provides relevant information and has the potential to be applied in forest and yield models for adaptive forest management under future climate change.

\section{Acknowledgments}

This work was supported by the National Natural Science Foundation of China (31270679 and 41271120). We highly appreciate the assistance of the Jilin Academy of Forestry for setting the study plots and the China Meteorological Data Sharing Service System for sharing climate data. We thank the computer network department in the Institute of Forest Resource Information Techniques, the Chinese Academy of Forestry for providing high-performance computer clusters for the parallel computing of climate interpolation. We are so grateful to two anonymous reviewers for their valuable comments that greatly improved our manuscript.

\section{References}

Aertsen W, Kint V, Van Orshoven J, Ozkan K, Muys B (2010). Comparison and ranking of different modelling techniques for prediction of site index in Mediterranean mountain forests. Ecological Modeling 221: 1119-1130. - doi: 10.1016/j. ecolmodel.2010.01.007

Aertsen W, Kint V, Van Orshoven J, Muys B (2011). Evaluation of modelling techniques for forest site productivity prediction in contrasting ecoregions using stochastic multi-criteria acceptability analysis (SMAA). Environmental Modeling and Software 26: 929-937. - doi: 10.1016/j. envsoft.2011.01.003

Albert M, Schmidt M (2009). Climatic-sensitive modeling of site-productivity relationships for Norway spruce (Picea abies (L.) Karst.) and common beech (Fagus sylvatica L.). Forest Ecology and Management 259: 739-749. - doi: 10.1016/j.foreco.2009.04.039

Afif-khouri E, Álvarez-Álvarez P, Fernández-López MJ, Oliveira-Prendes JA, Cámara-Obregón A (2011). Influence of climate, edaphic factors and tree nutrition on site index of chestnut coppice stands in north-west Spain. Forestry 84: 385-396. - doi: 10.1093/forestry/cpr025

Austin MP (2002). Spatial prediction of species distribution: an interface between ecological theory and statistical modeling. Ecological Modeling 157: 101-118. - doi: 10.1016/S0304-3800 (02)00205-3

Badeau V, Dupouey JL, Becker M, Picard JF (1995). Long-term growth trends of Fagus sylvatica L. in northeastern France: a comparison be- 
tween high and low density stands. Acta Oecologica 16: 571-583. [online] URL: http://cat.inist.fr $/$ ?aModele $=$ afficheN\&cpsidt $=2997892$ Bontemps JD, Herve JC, Dhote JF (2009). Longterm changes in forest productivity: a consistent assessment in even-aged stands. Forest Science 55: 549-564. [online] URL: http://www.ingentaconnect.com/content/saf/fs/2009/00000055/0000 0006/art00008

Bravo-Oviedo A, Del Río M, Montero G (2007). Geographic variation and parameter assessment in generalized algebraic difference site index modeling. Forest Ecology and Management 247: 107-119. - doi: 10.1016/j.foreco.2007.04.034 Bravo-Oviedo A, Gallardo-Andrés C, Del Río M, Montero G (2010). Regional changes of Pinus pinaster site index in Spain using a climate-based dominant height model. Canadian Journal of Forest Research 40: 2036-2048. - doi: 10.1139/X 10-143

Bravo-Oviedo A, Roig S, Bravo F, Montero G, Del Río M (2011). Environmental variability and its relationship to site index in Mediterranean maritime pine. Forest Systems 20: 50-64. - doi $10.5424 / \mathrm{fs} / 2011201-9106$

Carmean WH (1975). Forest site quality evaluation in the United States. Academic Press, USA vol. 27, pp. 209-267. - doi: 10.1016/S0065-2113 (08)70011-7

Charru M, Seynave I, Morneau F (2010). Recent changes in forest productivity: an analysis of national forest inventory data for common beech (Fagus sylvatica L.) in north-eastern France. Forest Ecology and Management 260: 864-874. doi: 10.1016/j.foreco.2010.06.005

Chen HYH, Krestov PV, Klinka K (2002). Trembling aspen site index in relation to environmental measures of site quality at two spatial scales. Canadian Journal of Forest Research 32: 112119. - doi: 10.1139/X01-179

Chiang JM, Iverson LR, Prasad AM, Brown KJ (2008). Effects of climate change and shifts in forest composition on forest net primary production. Journal of Integrative Plant Biology 50: 1426-1439. - doi: 10.1111/j.1744-7909.2008.00 749.x

Clark M (2013). Generalized additive models: getting started with additive models in R. Center for Social Research, University of North Dame, Notre Dame, IN, USA, pp. 13.

CMDSSS (2011). China meteorological data sharing service system. Web site. [in Chinese] [online] URL: http://cdc.cma.gov.cn

Cook ER, Kairiukstis LA (1989). Methods of dendrochronology: applications in the environmental sciences. Kluwer Academic Publishers, Dordrecht, The Netherlands, pp. 25-26. [online] URL: http://books.google.com/books?id=zr8Ucld6FYcC

Coops NC, Hember RA, Waring RH (2010). Assessing the impact of current and projected climates on Douglas-fir productivity in British Columbia, Canada, using a process-based model (3PG). Canadian Journal of Forest Research 40: 511-524. - doi: 10.1139/X09-201

Frescino TS, Edwards TCJ, Moisen GG (2001).
Modeling spatially explicit forest structural attributes using generalized additive models. Journal of Vegatation Science 12: 15-26. - doi: 10.1111/j.1654-1103.2001.tb02613.x

Fontes L, Bontemps JD, Bugmann H, Van Oijen M, Gracia C, Kramer K, Lindner M, Rötzer T, Skovsgaard JP (2010). Models for supporting forest management in a changing environment. Forest Systems 19: 8-29. [online] URL: http://recyt.fecyt.es/index.php/IA/article/viewArticle/931 5

Hamel B, Bélanger N, Paré D (2004). Productivity of black spruce and Jack pine stands in Quebec as related to climate, site biological features and soil properties. Forest Ecology and Management 191: 239-251. - doi: 10.1016/j.foreco.2003.12.00 4

Hastie T (1990). R: generalized additive models. Chapman \& Hall, London, UK, pp. 3-4.

Hutchinson MF (2006). ANUSPIN version 4.36 user guide. The Australian National University, Canberra, ACT, Australia, pp. 2-13.

IPCC (2007). Summary for Policymakers. In: "Climate Change 2007: Contribution of Working Group to the Fourth Assessment Report of the Intergovernmental Panel on Climate Change". Cambridge University Press, Cambridge, UK and New York, NY, USA, pp. 12-16.

Johnson M, Williamson T (2005). Climate change implications for stand yields and soil expectation valves: a northern Saskatchewan case study. The Forestry Chronicle 81: 683-690. - doi: 10.5558/ tfc81683-5

Kellomäki S, Peltola H, Nuutinen T, Korhonen KT, Strandman H (2008). Sensitivity of managed boreal forests in Finland to climate change, with implications for adaptive management. Biological Sciences 363: 2339-2349. - doi: 10.1098/ rstb.2007.2204

Kirilenko AP, Sedjo RA (2007). Climate change impacts on forestry. Proceeding of the National Academy of Sciences USA 104: 19697-19702. doi: 10.1073/pnas.0701424104

Kirschabum MF, Watt MS, Tait A, Ausseil AGE (2012). Future wood productivity of Pinus radiata in New Zealand under expected climatic changes. Global Change Biology 18: 1342-1356. - doi: 10.1111/j.1365-2486.2011.02625.x

Latta G, Temesgen H, Barrett T (2009). Mapping and imputing potential productivity of Pacific Northwest forests using climate variables. Canadian Journal of Forest Research 39: 1197-1207. doi: 10.1139/X09-046

Li F (2006). The response of distribution and NPP of Larix gemelinii forest to climate change. Master thesis, Institute of Botany, Chinese Academy of Science, Beijing, China, pp. 36. [in Chinese]

Liang WJ, Wang XC, Liu FJ (1999). Site index of main species in Jilin Province. Jilin Forest Science and Technology 143: 1-5. [In Chinese with English abstract]

Loustau D, Bosc A, Colin A, Ogée J, Davi H, François C, Dufrêne E, Déqué M, Cloppet E, Arrouays D, Le Bas C, Saby N, Pignard G, Hamza N, Granier A, Bréda N, Ciais P, Viovy N, Delage $F$ (2005). Modeling climate change effects on the potential production of French plains forests at the sub-regional level. Tree Physiology 25: 813823. - doi: 10.1093/treephys/25.7.813

Lutz DA, Shugart HH, White MA (2013). Sensitivity of Russian forest timber harvest and carbon storage to temperature increase. Forestry 86 : 283-293. - doi: 10.1093/forestry/cps086

Mäkelä A, Del Río M, Hynynen J, Reyer C, Soares P, Van Oijen M, Tomé M (2012). Using stand-scale forest models for estimating indicators of sustainable forest management. Forest Ecology and Management 285: 164-178. - doi: 10.1016/j.foreco.2012.07.041

Medlyn BE, Duursma RA, Zeppel MJB (2011). Forest productivity under climate change: a checklist for evaluating model studies. Interdisciplinary Reviews: Climate Change 2: 332-355. doi: $10.1002 /$ wcc. 108

Meng XY (2006). Forest measurement ( $3^{\text {rd }}$ edn). China Forestry Press, Beijing, China, pp. 106111. [in Chinese]

Messaoud Y, Chen HYH (2011). The influence of recent climate change on tree height growth differs with species and spatial environment. PLOS One 6: e14691. - doi: 10.1371/journal.pone.001 4691

McKenney D, Pedlar J (2003). Spatial models of site index based on climate and soil properties for two boreal tree species in Ontario, Canada. Forest Ecology and Management 175: 497-507. doi: 10.1016/S0378-1127(02)00186-X

Monserud RA, Rehfeldt GE (1990). Genetic and environmental components of variation of site index in inland Douglas-Fir. Forest Science 36: 1-9. [online] URL: http://www.ingentaconnect.com/content/saf/fs/1990/00000036/00000001/art 00002

Monserud RA, Huang SM, Yang YQ (2006). Predicting lodgepole pine site index from climatic parameters in Alberta. The Forest Chronicle 82: 562-571. - doi: 10.5558/tfc82562-4

Monserud RA, Yang YQ, Huang SM, Tchebakova $\mathrm{N}$ (2008). Potential change in lodgepole pine site index and distribution under climatic change in Alberta. Canadian Journal of Forest Research 38: 343-352. - doi: 10.1139/X07-166

Moss R, Babiker M, Brinkman S, Calvo E, Carter T, Edmonds J, Elgizouli I, Emori S, Erda L, Hibbard KA, Jones R, Kainuma M, Kelleher J, Lamarque JF, Manning M, Mathews B, Meehl J, Meyer L, Mitchell J, Nakicenovic N, O’Neill B, Pcihs R, Riahi K, Rose S, Runci P, Stouffer R, Van Vuuren D, Weyant J, Wilbanks T, Van Ypersele JP, Zurek M (2008). Towards new scenarios for analysis of emissions, climate change, impacts, and response strategies. IPCC Expert Meeting Report on New Scenarios. Intergovernmental Panel on Climate Change, Noordwijkerhout, the Netherlands, pp. 132.

Nigh G, Ying CC, Qian H (2004). Climate and productivity of major conifer species in the interior of British Columbia, Canada. Forest Science 50: 659-671. [online] URL: http://www.ingentaconnect.com/content/saf/fs/2004/00000050/0000 0005/art00008

Nigh G (2010). A closer look at site index - bio- 
geo-climatic site series correlations: Douglas-fir in the Coaster Hemlock Zone, xm2 variant, 01 site series. The Forest Chronicle 86: 477-483. doi: $10.5558 / \mathrm{tfc} 86477-4$

Nothdurft A, Wolf T, Ringeler A, Böhner J, Saborowski J (2012). Spatio-temporal prediction of site index based on forest inventories and climate change scenarios. Forest Ecology and Management 279: 97-111. - doi: 10.1016/j.foreco.2012. 05.018

Ollinger SV, Goodale CL, Hayhoe K, Jenkins JP (2008). Potential effects of climate change and rising $\mathrm{CO}_{2}$ on ecosystem processes in northeastern US forests. Mitigation and Adaption Strategies for Global Change 13: 467-485. - doi: 10.1007/s11027-008-9157-2

Peng CH, Jiang H, Apps MJ, Zhang YL (2002). Effects of harvesting regimes on carbon and nitrogen dynamics of boreal forests in central $\mathrm{Ca}$ nada: a process simulation. Ecological Modeling 155: 177-189. - doi: 10.1016/S0304-3800(02)00 134-5

Peng CH, Zhou XL, Zhao SQ, Wang XP, Zhu B, Piao SL, Fang JY (2009). Quantifying the response of forest carbon balance to future climate change in northeastern China: model validation and prediction. Global Planet Change 66: 179194. - doi: 10.1016/j.gloplacha.2008.12.001

Pinno BD, Paré D, Guindon L, Bélanger N (2009). Predicting productivity of trembling as- pen in the Boreal shield ecozone of Quebec using different sources of soil and site information. Forest Ecology and Management 257: 782789. - doi: 10.1016/j.foreco.2008.09.058

Qu JH, Wang J, Sun L (2008). Prediction of climate and utilizable precipitation change in northeast China using IPCC-AR4 models data. In: Proceedings of the conference "Climate Change at the Venue". Bejing (China) 20-22 Nov 2008. The Chinese Meteorological Society, Bejing, China, pp. 341-351. [in Chinese with English abstract]

R Development Core Team (2007). R: a language and environment for statistical computing. R Foundation for Statistical Computing, Vienna, Austria, pp. 1693. [online] URL: http://www.rproject.org

Skovsgaard JP, Vanclay JK (2008). Forest site productivity: a review of the evolution of dendrometric concepts for even-aged stands. Forestry 81: 13-31. - doi: 10.1093/forestry/cpm041 Skovsgaard JP, Vanclay JK (2013). Forest site productivity: a review of spatial and temporal variability in natural site conditions. Forestry 86 : 305-315. - doi: 10.1093/forestry/cpt010

SFA (2008). National forest resources statistics (2004-2008). State Forestry Administration, Bejing, China, pp. 233. [in Chinese]

Tang SZ, Lang KJ, Li HK (2009). Statistical and mathematical models of biological computing
(ForStat user guide). Science Press, Beijing, pp. 295-308. [in Chinese]

Tao FL, Zhang Z (2010). Dynamic responses of terrestrial ecosystems structure and function to climate change in China. Journal of Geophysical Research 115: 1-20. - doi: 10.1029/2009JG0010 62

Valentine HT (1997). Height growth, site index, and carbon metabolism. Silva Fennica 31: 51263. - doi: 10.14214/sf.a8524

Van Vuuren DP, Edmonds J, Kainuma M, Riahi K, Thomson A, Hibbard K, Hurtt GC, Kram T, Krey V, Lamarque JF, Masui T, Meinshausen Malte, Nahicenovic N, Smith SJ, Rose SK (2011). The representative concentration pathways: an overview. Climate Change 109: 5-31. doi: 10.1007/s10584-011-0148-z

Weiskittel AR, Crookston NL, Radtke PJ (2011). Linking climate, gross primary productivity and site index across forests of the western United States. Canadian Journal of Forest Research 41 : 1710-1721. - doi: 10.1139/X11-086

Wood S (2006). Generalized additive models: an introduction with R. Chapman \& Hall, CRC, Boca Raton, FL, USA, pp. 8-15.

Zhao ZC, Luo Y (2007). Projections of climate change over northeast China for the $21^{\text {st }}$ century. Journal of Meteorology Environment 23: 1-4. [in Chinese with English abstract] 